BMJ Nutrition,

Prevention \& Health

\section{Parity and the use of folic acid supplementation during pregnancy}

${ }^{1}$ Maccabi Institute for Research and Innovation, Maccabi Healthcare Services, Tel Aviv, Israel

${ }^{2}$ Sackler Faculty of Medicine, Tel Aviv University, Tel Aviv, Israel ${ }^{3}$ Harvard T.H. Chan School of Public Health, Harvard University, Cambridge, Massachusetts, USA

Correspondence to Sarah Sharman Moser; moser_sa@mac.org.il

SSM and MR contributed equally.

Received 21 January 2019 Revised 25 March 2019 Accepted 13 April 2019 Published Online First 19 May 2019
Check for updates

(C) Author(s) (or their employer(s)) 2019. Re-use permitted under CC BY-NC. No commercial re-use. See rights and permissions. Published by BMJ.

To cite: Sharman Moser S, Rabinovitch M, Rotem R, et al. bmjnph 2019;2:30-34.

\section{ABSTRACT}

Objective Folic acid (FA) supplementation has long been recommended before and during pregnancy to reduce the risk of neural tube defects. Factors influencing adherence to FA supplementation have been extensively evaluated, but little is known on the effect of parity. This study comes to examine the association between parity and maternal use of FA prior to and during pregnancy.

Methods In this retrospective population-based study, we identified mothers $(\mathrm{N}=228555)$ of all children $(\mathrm{N}=578204)$ born between the years 2000 and 2016 among members of a large health provider in Israel. Data on FA supplementation purchases were obtained from centralised medical databases.

Results The median (IQR) total dose of FA purchased 12 months prior to child birth among previously nulliparous women (120 mg, 48-240) was significantly $(p<0.001)$ higher than the dose purchased by women with one (90 mg (39-202)) and two prior births (84 mg (36-182)). The dose was even lower in women for three or more prior births (75 mg (36-165)). Despite the overall increasing secular trend in FA purchases during the study period, the negative relationship with parity remained.

Conclusions Adherence to FA supplementation is negatively associated with parity. Women with increasing parity may be at higher risk for pregnancy complications associated with low FA levels. The results of this study may inform the design of interventions to specifically increase adherence to FA supplementations among multiparous women.

Folic acid (FA) supplementation has long been recommended before and during pregnancy to reduce the risk of neural tube defects (NTDs). ${ }^{1-3}$ A series of observational and interventional studies have found that FA supplementation of the recommended daily dose $(400 \mu \mathrm{g})$ can prevent up to $72 \%$ of NTDs. ${ }^{4-6}$ Subsequently, the Food and Drug Administration has mandated programmes for fortification of grain-based food with $\mathrm{FA}^{4} 7$ in the USA, where flour has been enriched since 1996 to provide an estimated of 100-200 $\mu \mathrm{g}$ of FA supplementation per day to women of childbearing age. While many countries implemented similar enrichment programmes, no such programmes currently exist in the EU or in Israel. ${ }^{8}$
Nutritional folate consumption is not sufficient for optimal reduction of NTD risk, therefore many countries encourage women to take an FA supplement from 3 months before conception and during the first 12 weeks of pregnancy. ${ }^{6}$ In Israel, the Ministry of Health $(\mathrm{MoH})$ currently recommends doses ranging from $400 \mu \mathrm{g} /$ day to $800 \mu \mathrm{g}$ /day for low-risk pregnancies to as high as $4000 \mu \mathrm{g} /$ day for high-risk pregnancies (such as those with a previous NTD)..$^{5}$ A 2012 report suggested a $22 \%$ reduction in NTDs rates in Israel after the release of these $\mathrm{MoH}$ recommendations in 2000, from 11.7 cases per 10 000 live births in 1999 to 9.1 cases per 10000 births in $2010 .^{10}$

FA supplements and prenatal vitaims in Israel are subsidised by the government through the National Health Insurance Act and are available to all women at low cost. Nonetheless, adherence with FA supplementation before and during pregnancy is relatively low with only $39 \%$ of Jewish women adhering to the recommendation. ${ }^{11}$ The issue of low adherence with recommendations is of particular concern in unplanned pregnancies. According to one study, ${ }^{12}$ only $7 \%$ of childbearing women who did not plan their pregnancy have taken preconception FA supplementation for the recommended 12 weeks. Several sociodemographic factors have been found to affect adherence with FA supplementation during pregnancy, including maternal age, socioeconomic status (SES), ${ }^{13}$ level of education ${ }^{14}$ and immigration status. ${ }^{15}$ Parity has been shown to be negatively associated with adherence in several previous studies, but these were limited to self-reports ${ }^{16-18}$ and selective study populations. ${ }^{19}$ Studies were also limited to small number of multiparous women. For example, in a national survey among all maternity units in France, only $7 \%$ of interviewed women had a parity of 3 or above. ${ }^{20}$ In this study, we aimed at objectively examining the association between adherence with FA among 
pregnant women in Israel, a society characterised by high fertility rates.

\section{METHODS}

\section{Data source}

We used the computerised databases of Maccabi Healthcare Services (MHS), a 2.2 million member not-for-profit care provider, which provides health services to $25 \%$ of the total population in Israel. According to the National Health Act, MHS may not exclude applicants on any grounds, including age, state of health or religion. Therefore, all subpopulations are represented in the database, and MHS members have an age distribution similar to the general population. The MHS database integrates data from the MHS central laboratory, medication purchases throughout the MHS pharmacy network, physician consultations, hospitalisations, procedures and sociodemographic data since 1998. This method obviates the bias associated with retrospective self-reporting.

\section{Study population and design}

In this retrospective cohort study, we identified the mothers of all live births between the years 2000-2016. The index date was defined as the child's day of birth. To be included in the study, mothers had to have been continuously enrolled in Maccabi for at least 12 months before the index date. Written informed consent was not required as this study was a retrospective database analysis, and all data were anonymous.

\section{Assessment of exposure to FA during pregnancy}

We identified all purchases of FA supplementation from MHS databases, including dose and number of packs for 12 months before the index date. While FA supplements could also be purchased over the counter outside MHS, the cost is lower (eg, $\$ 5$ compared with $\$ 12$ for 100 tabs of $400 \mu \mathrm{g})$ if the purchase is made within the system.

\section{Study variables}

Study variables included age of mother, region of residence, parity, calendar year at index and SES. SES was based on the poverty index of the mother's enumeration area, as defined by Israel's 2008 national census. The poverty index is based on several parameters including household income, educational level, crowding, physical conditions and car ownership. ${ }^{21}$ We also collected information on the following comorbid maternal conditions at index date using MHS's patient registries ${ }^{22}{ }^{23}$ : diabetes mellitus, hypertension, cardiovascular diseases, cancer and subfertility. In addition, we collected data on smoking status (ever, never and unknown) as documented in the electronic medical record.

\section{Statistical analysis}

Descriptive statistics were calculated for all variables of interest and compared using $\chi^{2}$ tests for categorical tests and the non-parametric Kruskal-Wallis test for continuous variables. Median and IQR total dosage of FA purchased in the 12-month period before birth of each child were calculated and compared by parity. Mean cumulative doses are also presented and adjusted for age of mother at birth of the child, SES and year of birth of the child after $\log$ transformation of original values.

Additionally, FA supplementation is considered most effective at preventing NTD during first trimester of pregnancy; therefore, we performed a sensitivity analysis in order to check the amount of FA that was purchased during these months and 3 months before onset of pregnancy. $\log$ transformation was used to reduce variability for the FA dose, and outliers were excluded (included: $\log \geq 1$ and $\log \leq 3$ ). All analyses were conducted using IBM SPSS Statistics for Windows, V.22.0, and a $p$ value $<0.05$ was considered statistically significant.

\section{RESULTS}

The study population consisted of 578204 children and 228555 mothers. The mean age of women on their first birth was $29.34(\mathrm{SD}=5.52), 37.7 \%$ of the women had their first birth before the age of 27 years, while $17.6 \%$ of the women had their first birth after the age of 35 years. The majority of women lived in the centre of the country $(67.3 \%)$ and more than half of the women had a medium to high SES $(66.7 \%$, table 1$)$.

Overall, $18.6 \%$ of women did not purchase FA at all in the year preceding birth of their child, with this value being lower for women with no previous live births $(14.2 \%)$ and higher for those with parity $\geq 3(25.2 \%$, table 2).

The median dose of FA purchased 12 months before the birth of the first child during the study period (120 $\mathrm{mg}, \mathrm{IQR}=48-240$ ) was significantly higher than the dose purchased 12 months before the birth of the second and third child $(90 \mathrm{mg}, \mathrm{IQR}=39-202$ and $84 \mathrm{mg}$, IQR=36-182 respectively; $\mathrm{p}<0.001)$. For the fourth birth and over, the dose was even lower ( $75 \mathrm{mg}, \mathrm{IQR}=36-165$, table 3 ). The dose reported is the total dose in mg purchased for the whole period; therefore, for nulliparous women, the median daily dose was $120 / 365=0.328 \mathrm{mg}$.

Parity was negatively associated with FA purchases even after stratification by mother's age at index date (figure 1), and similar results were found with stratification by calendar years (2000-2005 and 2006-2016, table 4).

When restricting the analysis to cumulative purchases during the first trimester $(\mathrm{n}=311$ 104), the total median FA dose for the nulliparous women was $48 \mathrm{mg}$ (median daily dose of $0.526 \mathrm{mg}$ ) and the amount of FA purchased decreased as parity increased (data not shown).

\section{DISCUSSION}

The study results clearly indicate a significant negative association between parity and adherence to FA supplementation purchases among pregnant women. This is in agreement with several previous studies. Surén et al 
Table 1 Study population characteristics at index date, for all mothers at the birth of their first child

\begin{tabular}{lc}
\hline & $\mathrm{N}=\mathbf{2 2 8} \mathbf{5 5 5}$ (n (\%)) \\
\hline $\begin{array}{l}\text { Year of child birth } \\
\text { 2000-2005 }\end{array}$ & $108475(47.5)$ \\
\hline $2006-2016$ & $120080(52.5)$ \\
\hline Age (years) of mother & \\
\hline$\leq 27$ & $86243(37.7)$ \\
\hline $28-31$ & $69295(30.3)$ \\
\hline $32-34$ & $32799(14.4)$ \\
\hline$\geq 35$ & $40218(17.6)$ \\
\hline District & \\
\hline Center & $153862(67.3)$ \\
\hline North & $39139(17.1)$ \\
\hline South & $35554(15.6)$ \\
\hline Socioeconomic status & \\
\hline 1-5 & $76114(33.3)$ \\
\hline 6 & $47279(20.7)$ \\
\hline 7-10 & $105162(46.0)$ \\
\hline Smoking & \\
\hline Never & $200122(87.6)$ \\
\hline Ever & $20488(9.0)$ \\
\hline Unknown & $7945(3.5)$ \\
\hline Comorbid conditions & \\
\hline Cardiovascular & $2486(1.1)$ \\
\hline Diabetes mellitus & $1070(0.5)$ \\
\hline Hypertension & $2232(1.0)$ \\
\hline Fencer & $1507(0.7)$ \\
\hline & $42389(18.5)$ \\
\hline Fcality register & \\
\hline
\end{tabular}

*Scale between 1 (lowest) to 10.

showed that as parity increased, the proportion of mothers consuming FA decreased: among previously nulliparous women, $44.6 \%$ of pregnant mothers consumed FA, compared with $19.4 \%$ of mothers with two or more prior births. ${ }^{24}$ Similar results were reported by another study

Table 2 Comparison of mothers who purchased at least once or did not purchase FA within year before birth of each child, by parity

\begin{tabular}{llll} 
& $\begin{array}{l}\text { No purchases } \\
\text { (N=107 278) (n } \\
(\mathbf{\%}))\end{array}$ & $\begin{array}{l}\text { At least one } \\
\text { purchase } \\
\text { (N=470 926) (n } \\
\text { (\%)) }\end{array}$ & P value \\
\hline Parity & $33731(14.2)$ & $202999(85.8)$ & $<0.01$ \\
\hline Nulliparous & $37624(20.0)$ & $150762(80.0)$ & \\
1 & $20377(22.3)$ & $71090(77.7)$ & \\
2 & $15546(25.2)$ & $46075(74.8)$ & \\
$\geq 3$ & & & \\
\hline
\end{tabular}

FA, folic acid.
Table 3 Folic acid supplementation (total $\mathrm{mg}$ ) purchased by mothers for the 12-month period to birth of child, for those with at least one purchase of FA and excluding outliers $(p<0.001)$

\begin{tabular}{llll}
\hline Parity & $\mathbf{n}$ & Median (IQR) & Ajdusted mean* (SD) \\
\hline Nulliparous & 199664 & $120(48-240)$ & $251(9)$ \\
1 & 149197 & $90(39-202)$ & $195(9)$ \\
2 & 70499 & $84(36-182)$ & $132(7)$ \\
$\geq 3$ & 45749 & $75(36-165)$ & $117(6)$
\end{tabular}

*Adjusted for age of mother at birth of the child, socioeconomic status and year of birth of the child after log transformation of original values.

FA, folic acid.

that examined the association between mothers' use of prenatal FA and risk of severe language delay using self-reported questionnaires to determine FA use. ${ }^{17}$

Our results are also consistent with previous studies that have shown that nulliparous mothers had increased adherence to prenatal recommendations and healthcare utilisation compared with multiparous women, suggesting that women who have had a previous normal pregnancy may fail to recognise important elements of care in subsequent pregnancies. $^{25} 26$

We additionally observed that during the 1-year period before birth, $18.6 \%$ of mothers did not have any purchase of FA. This is a significant improvement compared with previously published data from a national survey of 1860 women in Israel that showed that $61 \%$ did not consume FA before pregnancy ${ }^{11}$ and is comparable with a self-reported study that reported $29 \%$ non-compliance. ${ }^{27}$ Our

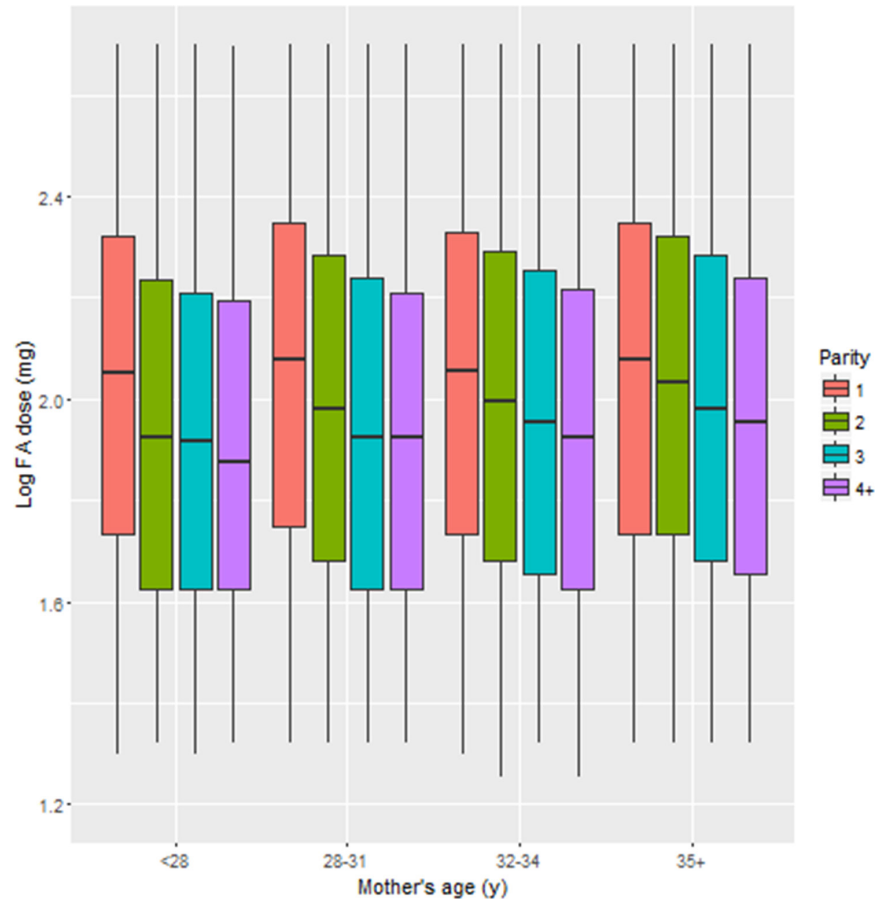

Figure 1 Log median cumulative dose of FA purchased by mothers for the 12-month period before birth, by mother's age, excluding outliers. FA, folic acid. 
Table 4 Median cumulative dose (total $\mathrm{mg}$ ) of FA purchased by mothers for the 12-month period before birth, by calendar year for those that purchased, and excluding outliers, n=465 109

\begin{tabular}{llrcl}
\hline Time period & Parity & N & Median (IQR) & P value \\
\hline 2000-2005 & Nulliparous & 94144 & $90(40.5-210)$ & $<0.001$ \\
& 1 & 53284 & $75(33-180)$ & \\
& 2 & 12502 & $63(30-150)$ & \\
& $\geq 3$ & 3810 & $60(30-147)$ & \\
2006-2016 & Nulliparous & 105520 & $135(60-270)$ & $<0.001$ \\
& 1 & 95913 & $96(42-210)$ & \\
& 2 & 57997 & $90(36-192)$ & \\
& $\geq 3$ & 41939 & $75(36-168)$ & \\
\hline
\end{tabular}

result additionally indicates that adherence to FA supplementation in Israel is greater than has been reported in a number of other countries. A study from the UK observed that the percentage of women who did not consume any amount of FA before and during pregnancy increased from $65 \%$ in $1999-2001$ to $69 \%$ in $2011-2012,{ }^{28}$ and other studies similarly estimated that $28 \%-50 \%$ of expectant women do not use FA supplementation. ${ }^{17} 24$ Our observation of an increase in use of FA supplementation over time from the year 2000 confirms previous finding from a national survey in Israel $^{11}$ that indicated an increase in adherence from $5.2 \%$ of pregnant women in the year 2000 to $39 \%$ in 2005 following the release of the Health Ministry recommendation concerning FA supplementations. ${ }^{29}$

Nulliparous women received median daily dose of FA for the year before childbirth of $0.328 \mathrm{mg}$, in agreement with guidelines, ${ }^{1130}$ whereas multiparous women received suboptimal daily doses of FA, a finding that is observed globally. ${ }^{31}$ Our analyses indicate that women with lower SES had decreased FA supplementation. Previous studies report similar results reflecting health inequalities in prenatal care for women with lower SES and ethnic minorities. ${ }^{32}$ A systemic review reported that younger age, less education, higher parity and lower SES led to inadequate prenatal healthcare utilisation. ${ }^{33}$

In addition to its large study population, the strengths of this study are its long-term, historical prospective and systematic exposure assessment. Our study has the limitation that data were unavailable before 1998, leaving some uncertainty regarding parity status of women giving birth in early years. However, the calculated median maternal age at birth of the first child in our study sample (29.34 years) is similar to the one reported for the Jewish population in Israel (28.65 years) as reported by the Israel Bureau of Statistics, ${ }^{34}$ suggesting that inaccuracy is probably minimal. Missing data about purchasing FA supplementation outside the network is another potential information bias in this analysis but seems to be non-differential and therefore should not have affected study conclusions, although may have negatively affected the median dose calculated in this study. Moreover, the proportion of non-compliance is relatively low suggesting that purchasing outside of the network is likely to be low. In addition, our analysis did not take into account interval between pregnancies that has been shown to affect preconception FA use.

\section{CONCLUSION}

Parity is negatively associated with adherence to FA supplementation. Further studies need to be carried out to develop interventions to increase adherence to FA supplementations, particularly in multiparous women.

Contributors Planning the research project: SSM, RR, GK, VS and GC. Conduction the research: SSM, MB, RR and GC. Reporting the research: all authors. Reviewing the manuscript: all authors.

Funding The authors have not declared a specific grant for this research from any funding agency in the public, commercial or not-for-profit sectors.

Competing interests None declared.

Patient consent for publication Not required.

Provenance and peer review Not commissioned; externally peer reviewed.

Data availability statement No data are available.

Open access This is an open access article distributed in accordance with the Creative Commons Attribution Non Commercial (CC BY-NC 4.0) license, which permits others to distribute, remix, adapt, build upon this work non-commercially, and license their derivative works on different terms, provided the original work is properly cited, appropriate credit is given, any changes made indicated, and the use is non-commercial. See: http://creativecommons.org/licenses/by-nc/4.0/.

\section{REFERENCES}

1. Group MVSR. Prevention of neural tube defects: results of the medical Research Council vitamin study. The Lancet 1991;338:131-7.

2. Czeizel AE, Dudás I. Prevention of the first occurrence of neural-tube defects by periconceptional vitamin supplementation. N Engl J Med 1992;327:1832-5.

3. Gucciardi E, Pietrusiak M-A, Reynolds DL, et al. Incidence of neural tube defects in Ontario, 1986-1999. CMAJ 2002;167:237-40.

4. Crider KS, Bailey LB, Berry RJ. Folic acid food FortificationIts history, effect, concerns, and future directions. Nutrients 2011;3:370-84

5. Green NS. Folic acid supplementation and prevention of birth defects. J Nutr 2002;132(8 Suppl):2356S-60.

6. Van Allen MI, Fraser FC, Dallaire L, et al. Recommendations on the use of folic acid supplementation to prevent the recurrence of neural tube defects. Clinical teratology Committee, Canadian College of medical geneticists. CMAJ 1993;149.

7. Control CfD, Prevention. CDC grand rounds: additional opportunities to prevent neural tube defects with folic acid fortification. MMWR Morbidity and mortality weekly report 2010;59.

8. Mills JL, Dimopoulos A. Folic acid fortification for Europe? BMJ 2015;351.

9. Rayburn WF, Stanley JR, Garrett ME. Periconceptional folate intake and neural tube defects. J Am Coll Nutr 1996;15:121-5.

10. Israel Ministry of Health. Open neural tube defects in Israel 19992010, 2012. Available: http://www.health.gov.il/PublicationsFiles/ NTDsummary2012.pdf

11. Israel Ministry of Health. Taking folic acid as recommended reduces the risk of open birth defects in the spinal canal; in addition it is possible to reduce the risk of birth defects in the heart and other systems by up to $30 \%$. Israel Ministry of Health 2006 [updated 08.07.2018]. Available: http://www.aisrael.org/_Uploads/1822777777. pdf

12. Cawley S, Mullaney L, McKeating A, et al. An analysis of folic acid supplementation in women presenting for antenatal care. J Public Health 2016;38:122-9.

13. Bixenstine PJ, Cheng TL, Cheng D, et al. Association between preconception counseling and folic acid supplementation before 
pregnancy and reasons for non-use. Matern Child Health $J$ 2015;19:1974-84.

14. Nelson CRM, Leon JA, Evans J. The relationship between awareness and supplementation: which Canadian Women know about folic acid and how does that translate into use? Can J Public Health 2014;105:e40-6.

15. Ben Natan M, Brandin Rimkus A, Tseytlin Eryomine A. Factors associated with intention of Israeli-born women and immigrant women from the former Soviet Union to take folic acid before and during pregnancy. Int J Nurs Pract 2018;24:e12622.

16. Nilsen RM, Vollset SE, Gjessing HK, et al. Patterns and predictors of folic acid supplement use among pregnant women: The Norwegian mother and child cohort study. Am J Clin Nutr 2006;84:1134-41.

17. Roth $\mathrm{C}$, Magnus $\mathrm{P}$, Schjølberg S, et al. Folic acid supplements in pregnancy and severe language delay in children. JAMA 2011;306:1566-73.

18. Jordi J, Joan F, Michelle M, et al. Maternal use of folic acid supplements during pregnancy and four-year-old neurodevelopment in a population-based birth cohort. Paediatric and Perinatal Epidemiology 2009;23:199-206.

19. Wilcox AJ, Lie RT, Solvoll K, et al. Folic acid supplements and risk of facial clefts: national population based case-control study. BMJ 2007;334.

20. Tort J, Lelong N, Prunet C, et al. Maternal and health care determinants of preconceptional use of folic acid supplementation in France: results from the 2010 National perinatal survey. BJOG 2013;120:1661-7.

21. Israel Central Bureau of Statistics. Characterization and classification of geographic units by the soci-economic level of the population 2008. publication No. 1530. Jerusalem, Israel, 2013. Report No: Publication No. 1530 Contract No: Publication No. 1530.

22. Shalev V, Chodick G, Goren I, et al. The use of an automated patient registry to manage and monitor cardiovascular conditions and related outcomes in a large health organization. Int $J$ Cardiol 2011;152:345-9.
23. Chodick G, Heymann AD, Shalev V, et al. The epidemiology of diabetes in a large Israeli HMO. European Journal of Epidemiology 2003;18:1143-6.

24. Surén $\mathrm{P}$, Roth $\mathrm{C}$, Bresnahan $\mathrm{M}$, et al. Association between maternal use of folic acid supplements and risk of autism spectrum disorders in children. JAMA 2013;309:570-7.

25. St Clair PA, Smeriglio VL, Alexander CS, et al. Situational and financial barriers to prenatal care in a sample of low-income, innercity women. Public Health Reports 1990;105:264-7.

26. Ribeiro ERO, Guimarães AMDN, Bettiol H, et al. Risk factors for inadequate prenatal care use in the metropolitan area of Aracaju, Northeast Brazil. BMC Pregnancy and Childbirth 2009;9.

27. Yagur Y, Anaboussi S, Hallak M, et al. Factors associated with compliance of folic acid consumption among pregnant women. Isr Med Assoc J 2017:19:494-8.

28. Bestwick JP, Huttly WJ, Morris JK, et al. Prevention of neural tube defects: a cross-sectional study of the uptake of folic acid supplementation in nearly half a million Women. PLOS ONE 2014;9:e89354.

29. Amitai Y, Fisher N, Haringman M. Increased awareness, knowledge and utilization of preconceptional folic acid in Israel following a national campaign. Preventive Medicine 2004;39:731-7.

30. Erickson JD. Folic acid and prevention of spina bifida and anencephaly. 10 years after the U.S. public health service recommendation. MMWR Recomm Rep 2002;51:1-3.

31. Ray JG, Singh G, Burrows RF. Evidence for suboptimal use of periconceptional folic acid supplements globally. BJOG: An Internal Journal of Obs Gyn 2004;111:399-408.

32. Ayoola AB, Nettleman MD, Stommel M, et al. Time of pregnancy recognition and prenatal care use: a population-based study in the United States. Birth 2010;37:37-43.

33. Feijen-de Jong EI, Jansen DE, Baarveld F, et al. Determinants of late and/or inadequate use of prenatal healthcare in high-income countries: a systematic review. Eur J Public Health 2012;22:904-13.

34. Statistics ICBo. Available: https://www.cbs.gov.il/he/Pages/default. aspx 